\title{
Chronic hepatitis B reactivation following infliximab therapy in Crohn's disease patients: need for primary prophylaxis
}

\author{
M Esteve, C Saro, F González-Huix, F Suarez, M Forné, J M Viver
}

Gut 2004;53:1363-1365. doi: 10.1136/gut.2004.040675

See end of article for authors' affiliations

......................

Correspondence to: Dr M Esteve, Department of Gastroenterology, Hospital Universitari Mútua de Terrassa, Plaça Dr Robert No 5, 08221 Terrassa, Barcelona, Catalonia, Spain; mestevecomas@ telefonica.net

Revised version received 16 March 2004 Accepted for publication 25 March 2004
Background: There is little information about the effect of infliximab on the clinical course of liver disease in Crohn's disease patients with concomitant hepatitis B virus (HBV) infection. Theoretically, immunosuppression induced by infliximab will facilitate viral replication which could be followed by a flare or exacerbation of disease when therapy is discontinued. There are no specific recommendations on surveillance and treatment of HBV before infliximab infusion. Two cases of severe hepatic failure related to infliximab infusions have been described in patients with rheumatic diseases.

Patients and methods: Hepatitis markers ( $C$ and $B$ ) and liver function tests were prospectively determined to 80 Crohn's disease patients requiring infliximab infusion in three hospitals in Spain.

Results: Three Crohn's disease patients with chronic HBV infection were identified. Two of the three patients with chronic HBV infection suffered severe reactivation of chronic hepatitis B after withdrawal of infliximab therapy and one died. A third patient, who was treated with lamivudine at the time of infliximab therapy, had no clinical or biochemical worsening of liver disease during or after therapy. From the remaining 80 patients, six received the hepatitis $B$ vaccine. Three patients had antibodies to both hepatitis $B$ surface antigen (anti-HBs) and hepatitis B core protein (anti-HBc) with normal aminotransferase levels, and one patient had positive anti-hepatitis $C$ virus (HCV) antibodies, negative HCV RNA, and normal aminotransferase levels. Except for the patients with chronic HBV infection, no significant changes in hepatic function were detected.

Conclusions: Patients with Crohn's disease who are candidates for infliximab therapy should be tested for hepatitis B serological markers before treatment and considered for prophylaxis of reactivation using antiviral therapy if positive. l: nfliximab is the treatment of choice for patients with moderately to severely active and fistulising Crohn's disease (CD) which is unresponsive to conventional treatment. Its use is contraindicated in the presence of active infection. However, recommendations with respect to prevention and treatment of infection before infliximab infusion mainly refer to bacterial and opportunistic infections. ${ }^{1}$ There is scarce information about the effect of immunomodulatory drugs on the clinical course of liver disease in CD patients with concomitant hepatitis B virus (HBV) or hepatitis C virus (HCV) infection. ${ }^{23}$ To date, the available information suggested that HCV and HBV infection should not influence treatment strategies for $\mathrm{CD}^{2-5}$ However, two cases of severe or fulminant $\mathrm{B}$ hepatitis ${ }^{7}$ related to infliximab therapy have been reported in patients with rheumatic diseases. More recently, a patient with chronic hepatitis B receiving lamivudine therapy requiring infliximab for ankylosing spondylitis showed no significant change in liver disease or viral replication. ${ }^{8}$

We report three CD patients and concomitant chronic hepatitis B from a cohort of $80 \mathrm{CD}$ patients treated with infliximab in three different hospitals in Spain. Two patients showed hepatitis B reactivation, with resolution of infection in one case and a fatal outcome in the other. The third patient, simultaneously treated with lamivudine, showed no clinical or biochemical effects on liver disease.

\section{PATIENTS AND METHODS}

From January 2000 to July 2003, 80 CD patients (45 men, 35 women; mean age 38.2 years (rangel4-80)) were treated with infliximab in three different hospitals in Spain. The number of infusions per patient ranged from 1 to 22 . Hepatitis C and B markers were prospectively determined before the first infliximab infusion in two hospitals as part of the baseline assessment prior to infliximab treatment. In the third hospital, serum was prospectively obtained before every infliximab infusion and stored in the serum bank. Hepatitis $C$ and $\mathrm{B}$ markers of all patients treated in this hospital were analysed in basal sera. Markers for HBV and HCV were identified using the following techniques: hepatitis B surface antigen (HBsAg), antibodies to hepatitis B surface antigen (anti-HBs), antibodies to hepatitis B core protein (anti-HBc), hepatitis B e antigen (HBeAg), antibodies to hepatitis B e antigen (anti-HBe), and anti-HCV were detected by the Roche (Roche Diagnostics, Basel, Switzerland) EIA method (Cobas Core II System), HCV RNA by the Roche PCR process (Cobas Amplicor HCV Monitor Test, v 2.0), and HBV DNA by Diagene's (Gaithesburg, Maryland, USA) Hybrid Capture II assay. Liver function tests were prospectively determined in the three hospitals before every infliximab infusion and two months after the last infusion. Aminotransferase levels (alanine aminotransferase (ALT), aspartate aminotransferase (AST)), alkaline phosphatase, gamma glutamyl transferase (GGT), and total bilirubin were measured by standard laboratory methods.

\section{RESULTS}

Three of 80 patients had chronic hepatitis B at the time of infliximab infusion, one with active viral replication. The case

Abbreviations: $\mathrm{CD}$, Crohn's disease, $\mathrm{HBV}$, hepatitis B virus; $\mathrm{HCV}$, hepatitis $C$ virus; anti-HBs, antibodies to hepatitis $B$ surface antigen; anti$H B c$, antibodies to hepatitis $B$ core protein; $H B s A g$, hepatitis $B$ surface antigen; $\mathrm{HBeAg}$, hepatitis $B$ e antigen; anti-HBe, antibodies to hepatitis $B$ e antigen; ALT, alanine aminotransferase; AST, aspartate aminotransferase; GGT, gamma glutamyl transferase 
reports of these three patients are described below in detail Six more patients received the hepatitis B vaccine several months before infliximab treatment and anti-HBs levels higher than $100 \mathrm{mIU} / \mathrm{ml}$ were detected before the first infusion. Three patients showed positivity for both anti-HBs and anti-HBc with normal aminotransferase levels, suggesting spontaneous resolution of infection months or years before infliximab treatment. One patient had positive antiHCV antibodies, negative HCV RNA, and normal aminotransferase levels. Except for patients with chronic hepatitis B infection, no significant changes in hepatic function were detected during infliximab therapy.

\section{Case No 1}

A 34 year old man was diagnosed with $C D$ of the ileocaecal and sigmoid area in August 2000. He was treated with prednisone $70 \mathrm{mg} /$ day and enteral nutrition, developing steroid dependence in the following six months. Mild hypertransaminasaemia was recorded and attributed to enteral nutrition. He was given azathioprine $2.5 \mathrm{mg} / \mathrm{kg} / \mathrm{day}$ in February 2001, and in May 2001 he developed a fistulous tract from the terminal ileum to the urinary bladder. Ciprofloxacin was added as maintenance treatment to avoid urinary sepsis, and infliximab was administered at a dose of $5 \mathrm{mg} / \mathrm{kg}$ with an induction regimen of three doses. Partial remission was observed but early relapse occurred and surgical resection of the intestinal segment was indicated. An additional infusion of infliximab 10 days before surgery was administered in order to reduce inflammation. Resection of $40 \mathrm{~cm}$ of the terminal ileum and of three fistulous ileovesical tracts was performed. Two months later the patient experienced malaise and nausea. Blood analysis disclosed increased levels of serum ALT (2089 IU/l), AST (1561 IU/l), alkaline phosphatase (540 IU/l), gamma glutamyl transferase (GGT $165 \mathrm{IU} / \mathrm{l}$ ), and total bilirubin ( $1.7 \mathrm{mg} / \mathrm{dl}$ ). Mild hypoalbuminaemia $(32 \mathrm{~g} / \mathrm{l})$ and a decrease in prothrombin rate $(75 \%)$ were also found and the patient was admitted to hospital. Abdominal ultrasonography was normal. Serum markers for hepatitis A virus, HCV, cytomegalovirus, Epstein-Barr virus, and herpes virus were negative. IgM anti-HBc antibodies and high serum HBV/DNA polymerase levels were detected $(10400 \mathrm{pg} / \mathrm{ml})$. Archival serum, obtained previous to the first infliximab infusion, was recovered and serological markers of $\mathrm{B}$ and delta agents were determined. Positive HBsAg, IgG anti-HBc, HBeAg, and HBV/ DNA, and negative anti-HBs, IgM anti-HBc, anti-HBe, as well as IgM and IgG anti-delta were detected. Thus acute hepatitis caused by HBV reactivation was diagnosed.

The clinical outcome was excellent and three months later serum AST and ALT levels returned to normal and seroconversion from HBeAg to anti-HBe was documented, HBsAg was cleared, and HBV/DNA was undetectable.

\section{Case No 2}

A 38 year old man was diagnosed with ileocaecal CD with severe fistulising disease in 1979. He required multiple surgical procedures, including ileal and segmental colonic resections, and he received repeated transfusions. In 1987, persistent elevation of ALT and AST were detected and chronic hepatitis B was diagnosed. In 1990, the patient developed jaundice and coluria, and acute exacerbation of hepatitis, and a sharp increase in ALT (1030 IU/l), AST (1100 IU/l), and GGT (255 IU/l) was detected. HBV markers showed positive HBsAg, IgM anti-HBc, and HBeAg, confirming reactivation of HBV. Delta and $\mathrm{C}$ viruses were negative. One month later, ALT and AST levels returned to normal and seroconversion from $\mathrm{HBeAg}$ to anti-HBe with persistent HBsAg was documented. No immunosuppressive drugs had been administered in the previous six months.
From 1993 to 2000, the patient was receiving azathioprine and metronidazole, maintaining perianal fistulous tracks with variable drainage. Liver function tests were not influenced by immunosuppression. In 2000, in spite of azathioprine therapy, perianal disease worsened with the appearance of multiple fistulous tracks arising in a strictured and inflamed anorectal area. Infliximab therapy with a three dose induction regimen was indicated and azathioprine was maintained. Hepatitis virus infection was previously assessed showing positive HBsAg, IgG anti-HBc, and anti-HBe, and negative HBeAg and HBV/DNA. Delta and $\mathrm{C}$ viruses were negative. Partial remission with decreased drainage and normalisation of laboratory parameters of inflammation occurred.

Three months after the last infliximab dose, the patient developed jaundice and coluria, malaise, and weight loss. Physical examination revealed mucocutaneous jaundice and reappearance of severe perianal disease. Blood analysis showed increased levels of ALT (2225 IU/l), AST (2146 IU/l), GGT (227 U/l ), total bilirubin $(24.1 \mathrm{mg} / \mathrm{dl})$, decrease in prothrombin rate $(50 \%)$, and elevation of serum $\alpha$-fetoprotein levels $(589 \mathrm{ng} / \mathrm{ml})$. The liver appeared normal on ultrasonography and there was no ascites. Serum markers of hepatitis A and C, cytomegalovirus, Epstein-Barr virus, and herpes virus were negative. Positive $\operatorname{IgM}$ anti-HBc antibodies, HBeAg, and high serum HBV/DNA polymerase levels were detected $(9000 \mathrm{pg} / \mathrm{ml})$. After initial improvement, the patient developed subacute hepatic failure with ascites, marked hyperbilirubinaemia $(29.8 \mathrm{mg} / \mathrm{dl})$, and hypoprothrombinaemia $(27 \%)$. The patient died of variceal bleeding, encephalopathy, and hepatorenal syndrome before he could undergo liver transplantation.

\section{Case No 3}

A 26 year old man was diagnosed with CD in 1995 due to perianal abscess and fistulas, and was shown to have extensive colitis with ileal and rectal sparing. He was initially managed with metronidazole and mesalazine with an acceptable response. Blood analysis at diagnosis showed normal liver function values. In June 1999, increased levels of ALT (67 IU/1) and AST (36 IU/l) were found, which persisted in subsequent controls. HBsAg, IgG anti-HBc, HBeAg, and HBV DNA were positive, and anti-HBs, anti-HBe, and IgM anti-HBc were negative. Other causes of liver damage such as HCV and delta viruses were ruled out and liver biopsy, performed in February 2000, confirmed a diagnosis of chronic hepatitis with mild portal and lobular activity without fibrosis. Lamivudine $100 \mathrm{mg}$ daily was started two months later showing a good response with HBeAg seroconversion, HBV/DNA clearance, aminotransferase normalisation, and positive HBsAg, which still persists.

In November 2001, the patient experienced a relapse of CD with severe perianal disease and was treated with azathioprine $2.5 \mathrm{mg} / \mathrm{kg} / \mathrm{day}$. In July 2003, infliximab was added to the treatment-due to recurrence of perianal disease with repeated abscess formation-after abscess drainage and seton placement. Three doses of infliximab were administered followed by eight weeks of maintenance treatment (two additional doses), resulting in a complete and sustained response. Lamivudine was also maintained and no flare up of HBV infection was detected in blood analysis performed every two months.

\section{DISCUSSION}

A frequency of HBV and HCV as high as $24 \%$ has been reported in patients with $\mathrm{CD}$, generally related to surgical procedures and blood transfusions. ${ }^{2}$ In our series of 80 patients treated with infliximab, a much lower prevalence rate than previously described was found $(7.5 \%$ and $1.2 \%$ for 
HBV and HCV, respectively). Immunosuppressive drugs in chronically infected patients may lead to enhanced viral replication with exacerbation of hepatitis. Hepatitis rebound generally occurs after immunosuppression withdrawal and the magnitude of the hepatocellular response theoretically depends on the potency of the immunosuppressors. ${ }^{9}$ However, in spite of a potentially harmful effect of infliximab therapy on the course of viral hepatitis, there is little information about the influence of this treatment in the course of coexistent viral hepatitis in CD patients. In addition, there are no specific recommendations for viral hepatitis surveillance in this setting.

Our first two cases showed typical signs of HBV infection in patients receiving immunosuppressive therapy. ${ }^{90}$ Acute flare of hepatitis occurred 2-3 months after infliximab withdrawal. In the first case, recovery to a normal immune response produced HBV clearance and HBeAg seroconversion. In contrast, in the second case, extensive cytolysis occurred that led to hepatic failure and death. Lamivudine, a reverse transcriptase inhibitor, has been used with success in the treatment of chemotherapy related HBV reactivation in patients with haemato-oncological neoplasms ${ }^{11}$ and in transplant recipients, ${ }^{12}{ }^{13}$ and it could be a therapeutic option in these patients. However, severe flare up, as was the case in patient No 2, with high levels of bilirubin at presentation, seem to be predictors of treatment failure. ${ }^{13}$ A similar scenario was described in two rheumatic patients treated with infliximab. ${ }^{67}$ In one case clear reactivation of HBV hepatitis was documented ${ }^{6}$; in the other, who required liver transplantation, no evidence of either serological or histological reactivation of $\mathrm{HBV}$ was demonstrated. ${ }^{7}$ Both patients were treated with lamivudine and showed normalisation of liver function tests and persistence of HBsAg.

In No case 3, lamivudine was effective in inducing HBeAg seroconversion and was useful as primary prophylaxis of HBV reactivation when infliximab was added to azathioprine therapy. Such a preventive effect has also been demonstrated in a patient with chronic hepatitis $\mathrm{B}$ and ankylosing spondylitis requiring infliximab therapy. ${ }^{8}$ In addition, lamivudine, as primary prophylaxis for HBV reactivation, has been used with success in a small series of patients treated with potent immunosuppressors ${ }^{12}$ and more recently in a case control study performed in patients with allogenic haematopoietic stem cell transplantation. ${ }^{14}$ Unfortunately, data on the long term benefits of lamivudine are limited and mutations in the polymerase gene may emerge as soon as 6-9 months after therapy, inducing lamivudine resistance. ${ }^{10}{ }^{15}$ In lamivudine resistant HBV mutants, adefovir dipivoxil is a therapeutic option and should be taken into account when long term infliximab therapy is foreseen. ${ }^{16}$

Three additional patients in the present series had positive antibodies to HBV, suggesting past infection. Aminotransferase levels in these patients remained within the normal range before and after infliximab therapy. However, it is important to note that reactivation can also occur in anti$\mathrm{HBC}$ positive HBsAg negative patients because HBV may persists even after serological recovery. ${ }^{16}{ }^{17}$ Thus infliximab should be administered with caution in these patients and liver function tests should be closely monitored.

In conclusion, our finding of reactivation of hepatitis B in HBsAg positive patients emphasises the need for careful monitoring of viral hepatitis infection in patients with inflammatory bowel disease requiring immunosuppressive therapy, particularly infliximab. Antiviral therapy (lamivudine or adefovir dipivoxil) should be administered to those patients requiring infliximab therapy who exhibit positive surface antigen (HBsAg) with or without active viral replication. In addition, hepatitis $\mathrm{B}$ vaccination should be routinely recommended in all CD patients at diagnosis.

\section{ACKNOWLEDGEMENTS}

The authors are grateful to Fernando Fernández-Bañares, MD, and Eduard Cabré, MD, for their valuable suggestions.

\section{Authors' affiliations}

M Esteve, M Forné, J M Viver, Department of Gastroenterology, Hospital Universitari Mútua de Terrassa, Terrassa, Catalonia, Spain C Saro, Department of Internal Medicine, Hospital de Cabueñes, Gijón, Asturias, Spain

F González-Huix, Department of Gastroenterology, Hospital Josep Trueta, Girona, Catalonia, Spain

F Suarez, Department of Gastroenterology, Hospital Juan Canalejo, La Coruña, Spain

\section{REFERENCES}

1 Schreiber S, Campieri M, Colombel JF, et al. Use of anti-tumour necrosis factor agents in inflammatory bowel disease. European guidelines for 20012003. Int J Colorectal Dis 2001;16:1-13.

2 Biancone L, Pavia M, Del Vecchio Blanco G, et al. Hepatitis B and C virus infection in Crohn's disease. Inflamm Bowel Dis 2001;7:287-94.

3 Biancone L, Del Vecchio Blanco G, Pallone F, et al. Immunomodulatory drugs in Crohn's disease patients with hepatitis B or $C$ virus infection. Gastroenterology 2002;122:593.

4 Holtmann MH, Galle PR, Neurath MF. Treatment of patients with Crohn's disease and concomitant chronic hepatitis $C$ with a chimeric monoclonal antibody to TNF. Am J Gastroenterol 2003;98:504-5.

5 Campbell S, Ghosh S. Infliximab therapy for Crohn's disease in the presence of chronic hepatitis C infection. Eur J Gastroenterol Hepatol 2001;13:191-2.

6 Ostuni P, Botsios C, Punzi L, et al. Hepatitis B reactivation in a chronic hepatitis $B$ surface antigen carrier with rheumatoid arthritis treated with infliximab and low dose methotrexate. Ann Rheum Dis 2003;62:686-7.

7 Michel M, Duvoux C, Hezode C, et al. Fulminant hepatitis after infliximab in a patient with hepatitis $B$ virus treated for an adult onset Still's disease. J Rheumatol 2003;30:1624-5.

8 Oniankitan O, Duvoux C, Challine D, et al. Infliximab therapy for rheumatic diseases in patients with chronic hepatitis B or C. J Rheumatol 2004;31:107-9.

9 Perrillo RP. Acute flares in chronic hepatitis B: The natural and unnnatural history of an immunologically mediated liver disease. Gastroenterology 2001; 120:1009-22.

10 Liaw Y-F. Hepatitis flares and hepatitis B e antigen seroconversion: Implication in anti-hepatitis B virus therapy. J Gastroenterol Hepatol 2003;18:246-52.

11 Rossi G. Prophylaxis with lamivudine of hepatitis B virus reactivation in chronic $\mathrm{HBsAg}$ carriers with hemato-oncological neoplasias with chemotherapy. Leuk Lymphoma 2003;44:759-66.

12 Lee WC, Wu MJ, Cheng CH, et al. Lamivudine is effective for the treatment of reactivation of hepatitis $B$ virus and fulminant hepatic failure in renal transplant recipients. Am J Kidney Dis 2001;38:1074-81.

13 Liu CJ, Lai MY, Lee PH, et al. Lamivudine treatment for hepatitis B reactivation in $\mathrm{HBs} A g$ carriers after organ transplantation: a 4-year experience. J Gastroenterol Hepatol 2001;16:1001-8.

14 Lau GK, He ML, Fong DY, et al. Preemptive use of lamivudine reduces hepatitis B exacerbation after allogeneic hematopoietic cell transplantation. Hepatology 2002;36:702-9.

15 Conjeevaram HS, Lok AS. Management of chronic hepatitis B. J Hepatol 2003;38(suppl 1):S90-103.

16 Tillmann HL, Wedemeyer H, Manns MP. Treatment of hepatitis B in special patient groups: hemodialysis, heart and renal transplant, fulminant hepatitis, hepatitis B reactivation. J Hepatol 2003;39:S206-11.

17 Marusawa H, Uemoto S, Hijikata M, et al. Latent hepatitis B virus infection in healthy individuals with antibodies to hepatitis $B$ core antigen. Hepatology 2000;31:488-95. 